\title{
Innovative Technology for Post-Pandemic Economic Recovery
}

\author{
Mohammed Ali Berawi ${ }^{*}$ \\ ${ }^{1}$ Faculty of Engineering, Universitas Indonesia, Kampus UI Depok, Depok 16424, Indonesia
}

The COVID-19 pandemic has had significant negative impacts on most countries' resilience having unleashed major health, social, and economic shocks. The trauma varies across countries and industries, and many governments have announced fiscal packages to fund substantially increased public health measures, social assistance for vulnerable people, and business activities in response to the consequent fall in incomes, loss of job opportunities, and price fluctuations. Businesses need to adapt their activities to a new post-COVID normal in ways that support a rapid recovery, and market intervention is required to create a rebound effect to regain consumer confidence. In particular, the crisis has created widespread need to adopt digital solutions.

Digital technologies have already played vital roles in maintaining a functioning society by enabling remote working, facilitating contactless business transactions, and automating corporate processes during the pandemic. They are helping to create the "new normal" by delivering innovative ways for almost any activity to be conducted with even more productive outcomes. These technologies can be used as a driver for economic development during the crisis and in the post-pandemic recovery to enhance national resilience; they are crucial for ensuring social and commercial continuity in these uncertain times.

\section{The Roles of Stakeholders}

The pandemic has forced business models to adapt, and this could have a beneficial impact on economic recovery. For example, many businesses have been required to adopt digital strategies in response to changing customer behavior, and, as a result, massive online platforms to digitalize and realign business operations using artificial intelligence have been created. Consequently, businesses can improve operational efficiency using these autonomous technologies, and more resilient production systems and supply chains can be created through this digital transformation of existing industries.

Emerging technologies that support automation and digitization can be used to create smart cities that will transform business and public services provision. Therefore, collaboration and coordination between technological, financial, and policy developments are now required to build digital competency and infrastructure for the post-pandemic economic recovery. Optimizing the benefits of technology will thus require solid government policy, private sector investment, and appropriate human resource allocation. Governments, in particular, need to take effective strategic decisions about transforming health, economic, and social sectors by adopting these innovative technologies. 
On the other hand, digital technologies might have the potential impact to widen socioeconomic inequality, for example by reducing human involvement in conventional jobs and requiring greater education and skill in the future workforce. Governments are therefore also required to continue any policies that support the digital transformation and enhancement of relevant skills in small and medium-sized enterprises (SMEs) to cope with the ongoing situation and to deliver full support to the creative industries ecosystem through digitalization such as in digital literacy, access, and infrastructure. Digital technologies will enable resilience in SMEs by giving them practical online tools and business platforms from internal production through to connecting with the market and their customers.

Such advancements will be a major push in speeding up the post-pandemic recovery when leveraging knowledge, technology, and data in relation to digital integration will be important. Digital technologies will improve our economic and social resilience.

\section{Enhancing Technological Capacity}

Technologies are invented and advanced to improve projects, products, or performance. In this issue, we are pleased to present twenty papers dedicated to technological development in science and engineering.

The first paper, by A. Farissi, M. El Oumami, and Z. Beidouri, investigates the lean principles adopted by Moroccan food companies. The authors argue that the quasi-partial adoption of some lean practices has strengthened operational performance.

Next, A. Suwandi, T.Y. Zagloel, and A. Hidayatno propose a model to control the risk of pipe failure on inventory systems which, they argue, improves the reliability of product handling, percentage of successful rework and the percentage of product deteriorated.

In the third paper, written by P. Naruetharadhol, W.A. Srisathan, M. Suganya, J. Jantasombut, S. Prommeta, and K. Chavis, the adoption of green innovation in the manufacturing industry is investigated. Adopting these innovations is shown to improve organizational structure through the integration and differentiation of systems and the strengthening of core competencies.

S. Butdee and U.Kanawapee present an approach to the quality prediction modelling of a preform fastener process using fuzzy logic and DEFORM simulation in the fourth piece. The authors argue that the model can be used to predict cold forging quality at the design stage and thus eliminate defects and reduce rework costs.

The fifth paper, by Y.A. Yatmo, M.M.Y Harahap, and P. Atmodiwirjo, proposes the Isolation Recovery House (IRH), an adaptable modular isolation unit, as a response to infectious disease outbreaks. IRH, it is asserted, could improve healthcare services during a pandemic; it is quick to construct, adaptable to various contexts, and meets minimum isolation space standards.

Subsequently, M. Asvial, J. Mayangsari, and A. Yudistriansyah investigate the e-learning intention of students due to the impact of COVID-19. The authors find strong demand for increasing digital literacy, minimizing digital gaps, improving teacher quality, and supporting online learning resources.

The seventh article, written by G.S. Harsha and P. Poluraju, presents a modified strut and tie method and truss reinforcement for shear strengthening reinforced concrete deep beams. This configuration is shown to be stronger than vertical shear reinforcement in resisting a $20 \%$ higher load.

S.S. Moersidik, L. Annasari, and R. Nugroho then evaluate the efficacy of advanced oxidation using cavitation ozonation in removing recalcitrant organic matter from landfill 
leachate. The authors argue that it is an effective pre-treatment approach because it increases the biodegradability of stabilized leachate and reduces the load on later treatment units.

The next paper, by J.U.D Hatmoko, P.K. Astuti, and S.N. Farania, investigates the use of insurance by contractors as a risk-response mechanism. Here, the authors suggest that the parties involved in an insurance process are more open and tend to use it as a means of sharing project risks rather than merely fulfilling contractual clauses.

The tenth piece, written by E. Yilmaz, T. Suzuki, K. Ito, G.J. Gotama, W. Anggono, and M. Ichiyanagi, investigates the effects of droplet size and velocity of water-glycerin mixtures under different conditions. The Sauter and arithmetic mean diameters are found to have a tendency to decrease as plate temperature, injection pressure, and viscosity are increased at specific observation areas.

In the eleventh paper, E.A. Syaefudin, G. Kiswanto, and A.S. Baskoro propose a five-axis peripheral milling method for sculptured surfaces based on a faceted model. The proposed method successfully maximized the machining area by up to $80 \%$.

D. Paroka, A.H. Muhammad, and S. Rahman then examine the hydrodynamic factors corresponding to weather criteria applied to a Ro-Ro ferry. The authors present a model to determine the parameters to be applied to ships with breadth-to-draught and verticalcenter-of-gravity-to-draught ratios larger than 3.50 and 1.50, respectively.

The thirteenth paper, by Warjito, Budiarso, K. Celine, and S.B.S Nasution, presents a computational method for finding the best nozzle geometry in the context of cross-flow turbine design since this dramatically affects turbine performance.

The next article written by I.K.A.P. Utama, W.D. Aryawan, A. Nasirudin, Sutiyo, and Yanuar, investigates the pressure and flow velocity distributions of a slender-body catamaran. The authors argue that the effect of hull interference variation can be recognized through the velocity augmentation and pressure change ratios and the viscous interference factor.

Sudarno, S. Soeparman, S. Wahyudi, and A.S. Widodo subsequently discuss the construction of a finned heat radiation reflector using a cut cone-shaped stainless-steel plate. The finned reflectors are found to increase the efficiency of liquefied petroleum gas stoves and enhance the area of complete combustion.

The sixteenth paper, written by A.H. Qurrahman, W. Wilopo, S.P. Susanto, and H.T.B.M. Petrus, explores energy efficiency and exergy loss in geothermal power plants. Based on a series of case studies, the authors find a lowest turbine efficiency of 67\%, a highest exergy loss of $50 \mathrm{Mw}$, and a highest inter-condenser energy change rate of $5.8 \times 104 \mathrm{~kW}$.

The next piece, by T. Soehartanto, R.A. Wahyuono, P.Y. Aisyah, and B. Ubaidillah, presents a design for simple water-absorption columns embedded with ultrasonic nebulizers for biogas purification. The authors show that $\mathrm{CO}_{2}$ and $\mathrm{H}_{2} \mathrm{~S}$ are dissolved in the water whilst $\mathrm{CH}_{4}$ is released on its surface using this ultrasonic approach.

In paper eighteen, H.T.B.M. Petrus, M. Olvianas, W. Astuti, and M.I. Nurpratama examine the effect of silica content, $\mathrm{NaOH}$ molarity, and curing temperature on compressive strength, and the authors find an optimum formulation at $130 \mathrm{~g}, 10 \mathrm{M}$, and $80^{\circ} \mathrm{C}$, respectively. This produces a compressive strength as high as $7.73 \mathrm{MPa}$.

A. Prasetya, R. Darmawan, T.L.B. Araujo, H.T.B.M. Petrus, and F.A. Setiawan investigate substrate consumption through a growth kinetics model of black soldier fly larvae in the nineteenth article and demonstrate its successful implementation.

The last paper, written by C. Niken, E. Tjahjono, and FX Supartono, develops a shrinkage-rheological model of high-performance concrete with compressive strength of 
$60 \mathrm{MPa}$. The model depends on product hydration growth and weather parameters as well as the number, size, and distribution of pores.

I hope that this issue of IJTech conveys new insights into the ways in which we conduct our research. I am pleased to accept and respond to any comments or enquiries about the journal's direction and content, and I invite you to join us in this venture by sending your work for consideration.

With warmest regards from Jakarta,

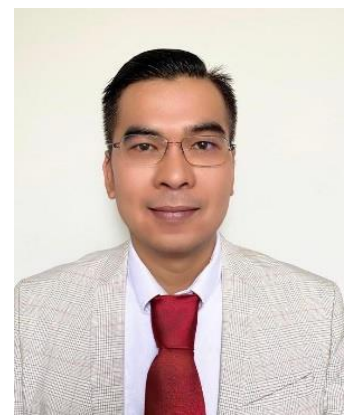

Dr. Mohammed Ali Berawi

Editor in Chief 